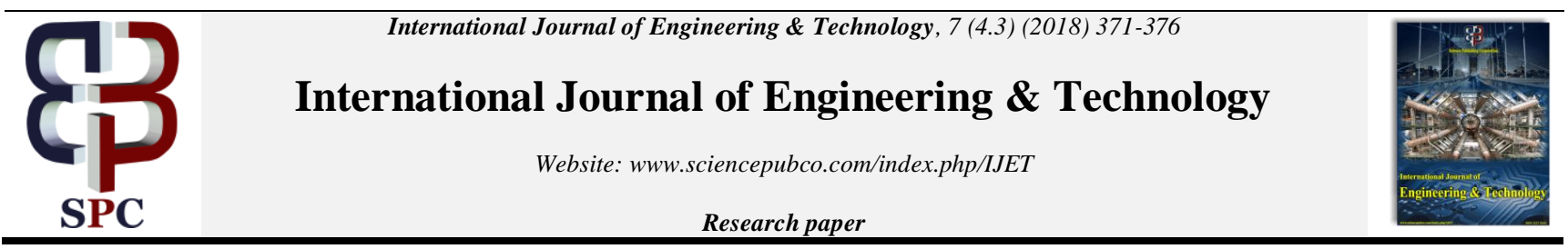

\title{
Efficiency Justification of the Special Tread Wheelset Passage Along Specific Track Section
}

\author{
Vladimír Hauser $^{1 *}$, Juraj Gerlici ${ }^{1}$, Olena Nozhenko ${ }^{2}$, Kateryna Kravchenko ${ }^{1}$, Mária Loulová ${ }^{1}$ \\ ${ }^{1}$ University of Žilina, Slovak Republic \\ ${ }^{2}$ Volodymyr Dahl East Ukrainian National University \\ *Corresponding author E-mail: vladimir.hauser@fstroj.uniza.sk
}

\begin{abstract}
In urban railway environments, the problem of tramcars passing small radius arches appears to be topical. In this regard is proposed that the wheelsets should be complemented on the outer side of the wheels with a second tread of a lower radius, intended exclusively for ride in arches of the track with a radius which the conventional wheelsets cannot even theoretically pass without creep. The complemented wheel tread enters into operation (or out of action) as a result of passing over a specially shaped rail located in the intersections before and behind the small radius arc. In this process, there is a step change in the wheel-rail contact location - similar to what is commonly used when riding on a facing rail located in the immediate vicinity of the point frog. The paper deals with the comparison of these two cases based on a simulation analysis of vehicle ride. The contact point change is evaluated by steering forces, angles of attack and the creep velocities. Four times longer service life of the proposed shaped rail than the one of a frog point is expected.
\end{abstract}

Keywords: curve-passing resistance, double tread, point frog, small radius track, tramcar wheelset.

\section{Introduction}

Rolling stock operated in the urban railways environment is a significant, efficient and environmentally friendly mass transit system that forms an indispensable part of modern cities. One of the demands placed on trams is the transition through arcs of very small radii. In many European cities, on tracks with a gauge of $1000 \mathrm{~mm}$, where curves with a radius of $50 \mathrm{~m}$ are common, under arduous conditions, arches of the track with a radius of $18 \mathrm{~m}$ and more are built [1].

The requirement to pass through a strongly curved section of the track is a major technical problem [2,3], since in such sections of the track an increased vehicle resistance $[4,5]$, wear of the rail wheel pair [6] and noise [7 - 9] of the vehicle appears. The current, in practice widely used solutions include, in particular, intensive lubrication of the curved sections of a track [10] along with the use of the noise-absorbing elements in the fastening of the rails - that is to say, a measure eliminating the adverse consequences without affecting the cause thereof. In bogie design, independent wheels mounted in the sub-frame are commonly used. Although this concept may improve arc passage under certain circumstances, it requires a complicated electronic-mechanical steering system [11] to ensure a correct ride, both in the arc and in the straight track.

In order to provide a simple and at the same time a fully-fledged solution for the passage of the vehicle through the track arc, the authors team proposed own solution, expanding the possibilities of rolling a wheelset consisting of a single rigid body. The proposed solution is to add a new tread to the outside of the wheels, as shown in Fig. 1.

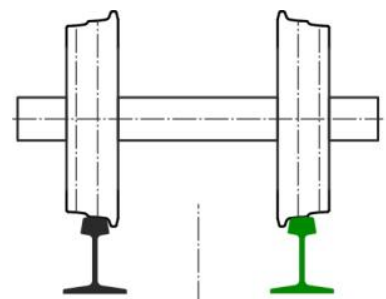

a)

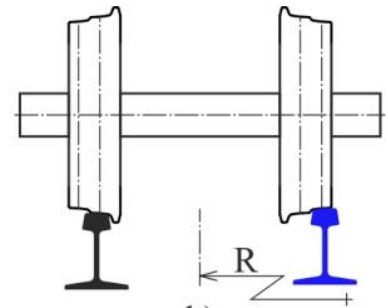

b)
Fig. 1: Wheelset with proposed tread design a) situated in straight track, b) situated in the small radius curve

The added tread has a smaller radius, it is intended for the ride in the arches of the track with a radius that the conventional wheelsets cannot even theoretically overcome without creep [12, 13]. Justification of the proposed solution can be given in the form of vehicle arc-passing power losses comparison in dependence to track radius. In Fig. 2 are shown power dissipation for vehicle similar to the T3 tram car [14] when running at speed $10 \mathrm{~km} / \mathrm{h}$. Three cases are compared - vehicle with original bogies, without the possibility to steer the wheelsets and without additional tread (Fig. 2a)); with the possibility to steer the wheelsets and without additional tread (Fig. 2b)) and with the possibility to steer the wheelsets and with the use of additional tread (Fig. 2c)). Power losses are given in Fig. 2 in the form of its components needed to cover the creep in longitudinal direction $\mathrm{P}_{\mathrm{x}}$ and in lateral direction $\mathrm{P}_{\mathrm{y}}$ are given separately, but the vehicle covers both power dissipations at the same time. 


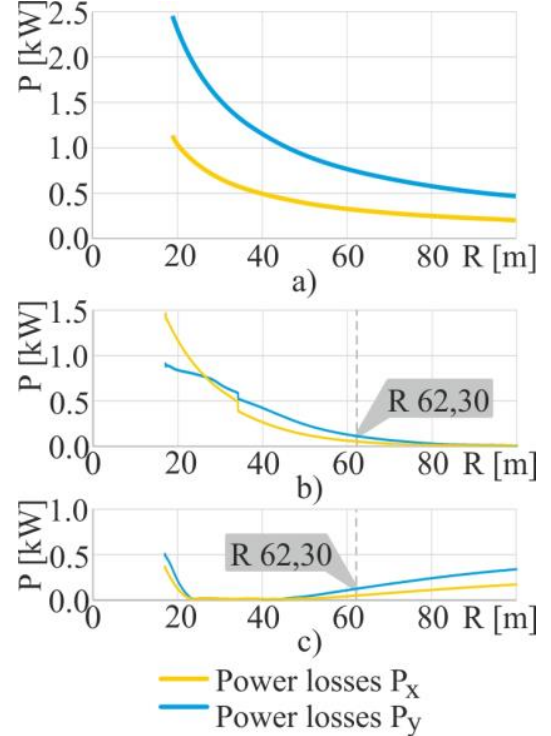

Fig. 2: Curved track passing power dissipation of the vehicle: a) without the possibility to steer the wheelsets and without additional tread,b) with the possibility to steer the wheelsets and without additional tread,c) with the possibility to steer the wheelsets and with the use of additional tread

When proposed wheelset is entering the arc, as shown in Fig. 3a), the rail-wheel contact point location changes - similar to the usual practice used for ride in the facing rails, located in the immediate vicinity of the point frog $[15,16]$, as shown in Fig. 3b).

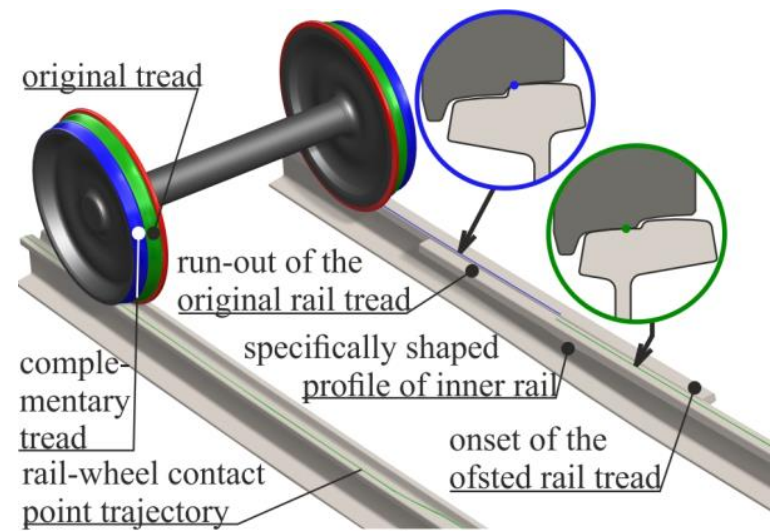

a)

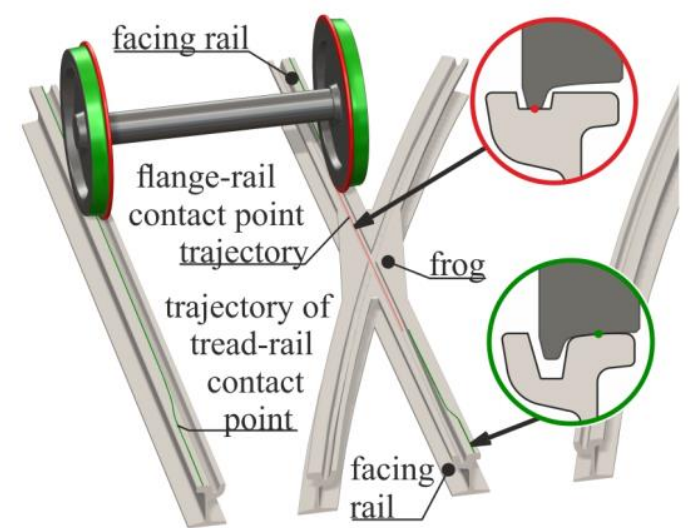

b)

Fig. 3: Visualization of the wheelset rail-wheel contact point relocation a) on entry into a small radius curve; b) on the city lines point frog

The aim of the paper is to provide a comparison of these two cases by simulation analysis of vehicle driving in the calculation program.

\section{The Method of Passing a Wheelset With Additional Tread Through an Arc of a Low Radius}

The proposed solution is based on the relation defining the minimum radius of the track arc $\mathrm{R}[\mathrm{mm}]$, which can be used by the conventional wheelsets to pass theoretically without creep [17]

$$
R=\frac{2 s r}{\Delta r}
$$

where $2 \mathrm{~s}[\mathrm{~mm}]$ - distance of the wheelset junction circles; $\mathrm{r}[\mathrm{mm}]$ - nominal radius of the wheel;

$\Delta \mathrm{r}[\mathrm{mm}]$ - the difference between the instant rolling radius of the left and right wheels of the wheel when the track channel clearance is exhausted.

The shape of the wheel tread is, as a rule, specific to the transport company of each city, taking into account specific traffic requirements. Modern profiles with proven good ride performance include, among other, the KP-1 profile [18], the characteristics of which can be shown by the following considerations: tramline wheelset, radius $r=340 \mathrm{~mm}$, located in a rail with the NT1 profile, reaching the distance of the contact circles $2 \mathrm{~s}=1061.9 \mathrm{~mm}$ and the value $\Delta \mathrm{r}=5.5 \mathrm{~mm}$ is according formula (1) theoretically able to pass the arc with a radius $\mathrm{R}=65.64 \mathrm{~m}$ without creep, which is in insufficient in urban conditions, such as the turnover and some crossings.

The minimization of the variable $\mathrm{R}$ in relation (1) in the proposed solution is realized by increasing the fraction denominator, while not affecting the existing geometry of the wheel profile. The relationship (1) is modified to the form (2), the solution described is shown in Fig. 2a)

$$
R=\frac{(2 s+y) r}{\Delta r+z}
$$

where $\mathrm{y}[\mathrm{mm}]$ - the lateral displacement of the complemented wheel tread;

$\mathrm{r}$ [mm] - nominal radius of the wheel;

$\mathrm{z}$ [mm] - distance of the vertical displacement of the complemented wheel tread.

The arc of the track of a lesser radius than the relationship (1) defines, is solved specifically - the inner rail is shifted in a vertical and lateral direction about the same values as is the complementary wheel tread shifted from the original one. The complemented wheel tread enters into operation (or acts out of action) as a result of passing over a specially shaped rail located in the track transition curve in places with a radius according to the relationship (1) before (or behind) the small radius curve. In this way, it is possible for the wheelset to create sufficient wheel radius difference when passing an arc. The desired, resp. the achievable value $\Delta \mathrm{r}$ depending on the radius of the arc of the track is graphically shown in Fig. 4.

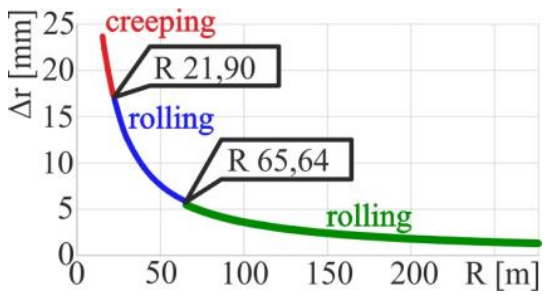

Fig. 4: Distribution of the radius of the track arc in terms of the possibility of its overcoming by rolling

In the described process, the rail-wheel contact location is changed from the original tread to the complemented part as shown in Fig. $3 a)$. The trajectories are drawn on the surface of the track belts 
where they are in contact with the passing wheelset obtained on the basis of the vehicle simulation analysis. The trajectory shows the ride of the first wheelset of the vehicle. This is a situation that needs to be evaluated in terms of phenomena occurring in the wheel-rail contact. As an analogous situation we can consider a ride through a facing rail, in common practice located in the immediate vicinity of the point frog of urban railways.

\section{The Method of Passing the Wheelset Through A Point Frog}

One of the specifics of city railways is the way the wheel passes through the frog of the point. This process $[19,20]$ differs fundamentally from conventional railways [21]. The tramline wheel has a smaller width, so it cannot safely create a two-point contact of the wheel tread with the tip of the frog and the wing rail necessary to overcome the gap created for the flange during the ride in a turning as it is commonly used in the conventional rail environment. The passage of a railway wheel through a point frog together with the comparison of the width of the railway and the tramline wheel is shown in Fig 5.

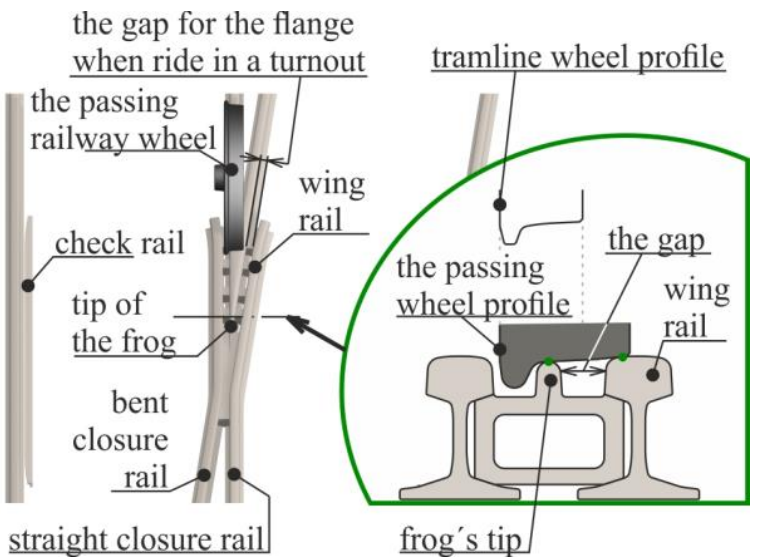

Fig. 5: Visualization of railway wheel passage through a point frog

Before passing a frog, the tramline wheel moves its contact point from the tread to the flange by passing it through the facing rail, then passes through the frog on the flange, allowing the wheel tread to pass over the gap created for the flange for ride to a deviation. Subsequently, a contact point is then transferred from the flange back to the tread thanks to the facing rail. The visualization of the passage of the tramline wheel through a city railway point frog is shown in Fig. 3b). The trajectories are drawn on the surface of the track belts where they are in contact with the passing wheelset, obtained on the basis of the simulation analysis of the vehicle ride. The displayed trajectory documents the ride of the first wheelset of the vehicle.

From the principle of passing the frog used by the tram wheel, it follows that the kinematic excitation of the vehicle is inevitably involved in this process, as the facing rail can be considered as a $14.6 \mathrm{~mm}$ high track unevenness. There is also a change in the rolling radius of the wheel given by the height of the flange and consequently to the change of the quantity $\Delta \mathrm{r}$, thus the wheelset has the tendency to roll over the curved trajectory, the radius of which can be determined from the relation (1) modified to the following form:

$$
R=\frac{(2 s-y) r}{\Delta r+h}
$$

where $\mathrm{y}[\mathrm{mm}]$ - the distance of the wheel contact circle during ride on the flange from its nominal position;

$\mathrm{h}[\mathrm{mm}]$ - height of the flange.
Comparison of the ride of wheelset with the added tread into an arc of small radius and the passage of the wheelset through facing rail and the frog was realized by simulation analysis of the vehicle ride in a calculation program.

\section{Simulation Analysis of the Vehicle Ride}

In the simulation analysis, a ride of a vehicle similar to T3 tram with its parameters [14] is contemplated, with the exception that the vehicle being considered in the simulation analysis is equipped with bogies with a mechanism for steering the wheelsets to a radial position in accordance to the angle between the bogie frame and the vehicle body. A detailed description of the vehicle simulation model has been published in publication [22].

Passing the investigated track sections with a gauge of $1,000 \mathrm{~mm}$ is considered at a constant speed of $10 \mathrm{~km} / \mathrm{h}$ without driving and braking forces. In the case of passing a point frog, the ride on a straight track is considered, the facing rails and the frog are located on the right rail. The facing rails have a length of $800 \mathrm{~mm}$, a longitudinal slope of the bottom of the groove of 1:32, the length of the rolling edge curvature run-out $600 \mathrm{~mm}$ [23]. To create the variable geometry of each facing rail, 9 profiles of cross section were created in a specific structure necessary to ensure compatibility with the computational program $[24,25]$. The following section, representing the frog, has a length of $1,000 \mathrm{~mm}$, with a crossing at the centre of this section including a gap for the flange for a ride into deviation. The crossing angle of the rails of $23^{\circ}$ represents a sudden change in rail geometry. For a correct processing of this change in the calculation program, it was necessary to define 101 cross-sections in the section of crossing $\pm 250 \mathrm{~mm}$. The described track section is shown in Fig. 6 .

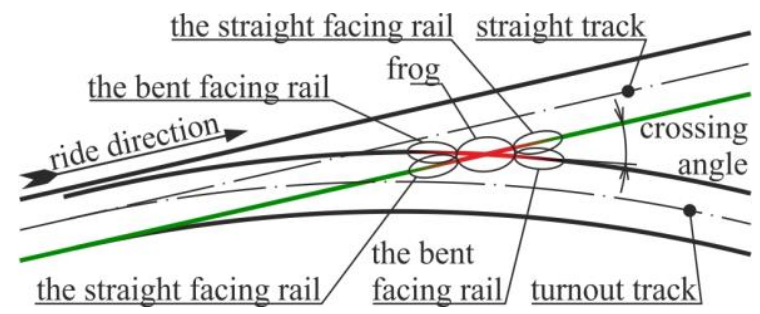

Fig. 6: Visualization of railway wheel passage through a point frog

In the case of an arc entry through a specially shaped rail allowing the transfer of the point of contact from the wheel tread to the complemented part, the ride in the clothoidal transition curve connecting the straight track with a right-hand rotated arc of a radius of $25 \mathrm{~m}$ is considered. The length of the transition curve is $10 \mathrm{~m}$, it is a tilted arc, where the beginning of the superelevation sine ramp is located in a straight line $5 \mathrm{~m}$ before the beginning of the transition curve. The superelevation of the outer rail belt in the arc is $33.6 \mathrm{~mm}$. Basically, this is a geometric arc solution based on the standard [26].

The shaped portion of the rail, i.e. the inner rail of the length of $1.5 \mathrm{~m}$, is designed so that when being passed over, there is no vertical deflection of the passing wheel. The run-out of the original rail tread, as well as the onset of the new tread, have a length of $750 \mathrm{~mm}$ and a longitudinal slope of 1: 250. The moment when the contact point is moved in theory occurs when the half-length of the shaped rail is passed. In order to create a variable geometry of the shaped rail, 12 profiles of the cross section were created in the specific structure necessary to ensure compatibility with the calculation program [24]. The described section of the line is shown in Fig. 7. 


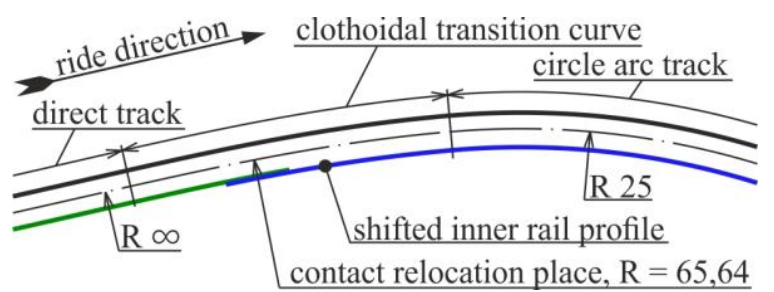

Fig. 7: Track considered in simulation when entering a small radius curve

Vehicle ride described by track sections was simulated in Simpack 9.10.1. [25].

\section{Comparison of Calculated Parameters Courses}

In order to compare the course of selected parameters of vehicle effects on the track, it is necessary to harmonize their time track, or another independent variable. In the presented graphs, the independent variable is the distance travelled by the vehicle along the track shown in Fig. 3a) and 3b), where the zero value of the distance travelled is the place where the first contact of the flange with the bottom of the groove, or the complemented tread and the shifted rail belt on the first wheelset of the vehicle, occurred.

The selected parameters of the wheel-rail contacts of the first bogie of the vehicle passing through the monitored track section are presented. In the following graphs (Figures 8 to 12), the shortened denomination of individual wheels is used:

$1 \mathrm{~L}-$ left wheel of the first wheelset,

$1 \mathrm{R}$ - right wheel of the first wheelset,

$2 \mathrm{~L}-$ left wheel of the second wheelset,

$2 \mathrm{R}$ - right wheel of the second wheelset.
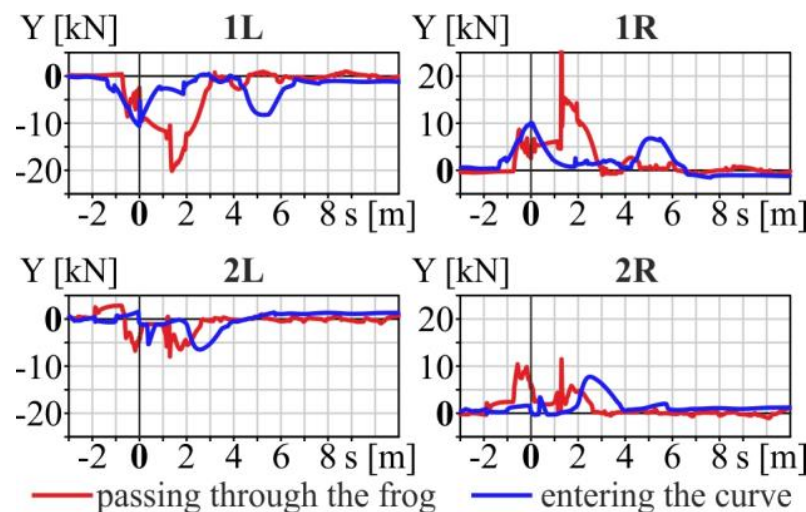

Fig. 8: Lateral forces on the individual wheels of the front bogie

Fig. 8 shows the course of the guiding forces during ride through the monitored track section. In the case of passing through a frog, it is possible to see the moment when the wheel enters the facing rail, which is manifested by the increase of the guiding forces at the point $\mathrm{s}=-0.8 \mathrm{~m}$. At the point $\mathrm{s}=1.3 \mathrm{~m}$, it is possible to see a sharp increase in the steering force caused by the re-positioning of the contact location on the tread. Changing the contact point when entering the arc also causes a certain increase in the steering force, but it is milder.
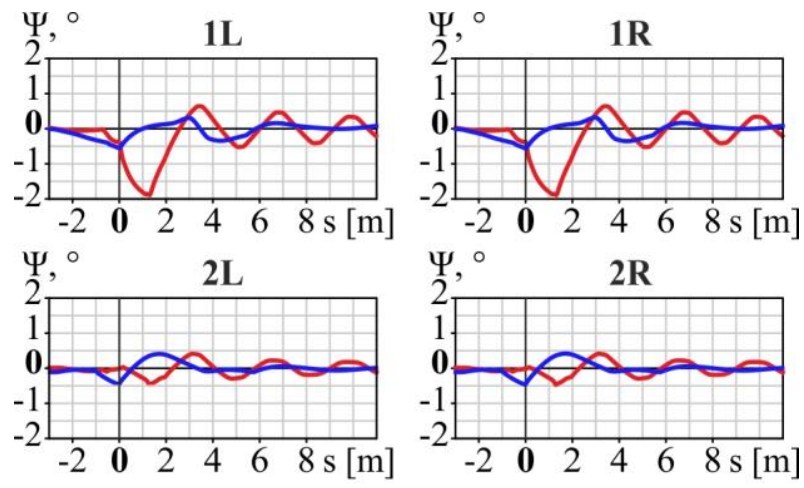

- passing through the frog

- entering the curve

Fig. 9: Courses of angles of attack on the individual wheels of the front bogie

From Fig. 9 it can be deduced that in both cases there is certain oscillation being induced in the vehicle. More significant increase in the angles of attack occurs on the first wheelset, reaching almost $2^{\circ}$. Entering the arc causes a larger increase in the angles of attack on the second wheelset, but the values do not reach $0.5^{\circ}$.
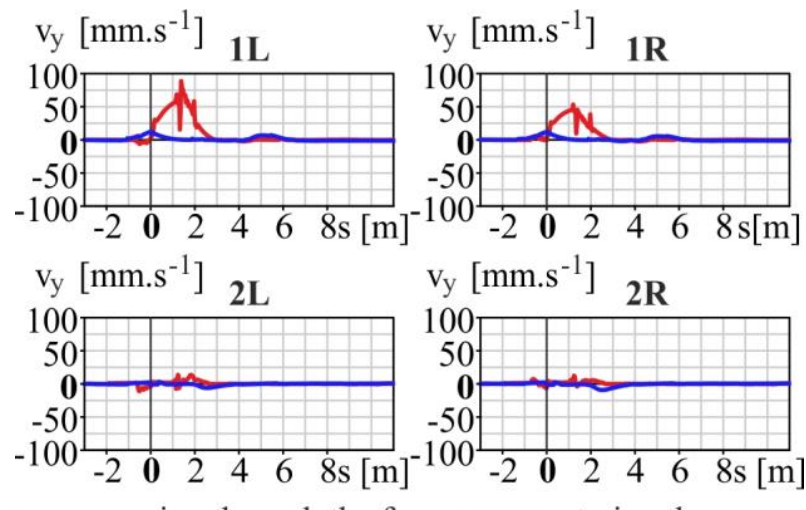

$\mathrm{v}_{\mathrm{y}}\left[\mathrm{mm} \cdot \mathrm{s}^{-1}\right]$

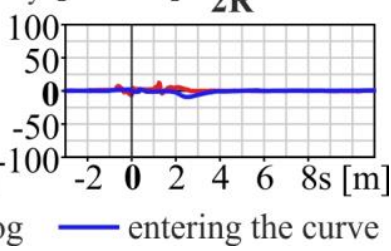

Fig. 10: Course of the lateral creep velocities on the individual wheels of the front bogie

Fig. 10 shows the course of lateral creep speed in the contact point. Extremely high values, approaching $100 \mathrm{~mm} \cdot \mathrm{s}^{-1}$, are achieved when passing through the frog. They are caused by the wheelset deflection from the position perpendicular to the track axis as a consequence of its rolling according to relation (3), although it is running in a straight track. A significantly more favourable course of the observed magnitude is reached when entering an arc where it does not exceed $15 \mathrm{~mm} . \mathrm{s}^{-1}$.

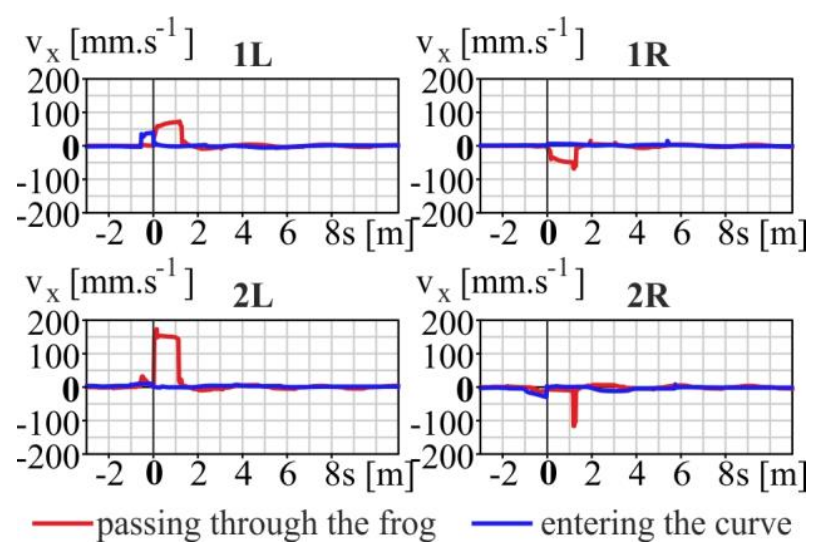

Fig. 11: Course of the longitudinal creep velocities on the individual wheels of the front bogie

The importance of the specially shaped rail geometry as well as the correctness of the proposed solution described by the relation 
(2) confirms the comparison of the longitudinal creep speeds shown in Fig. 11.

Changing of the contact point location in the process of passing a frog causes extremely high creep velocities values, which on some wheels exceed $100 \mathrm{~mm} \cdot \mathrm{s}^{-1}$. The entry into the track arc causes some increase in the longitudinal creep velocity, which for example on the attacking wheel is approaching $40 \mathrm{~mm} . \mathrm{s}^{-1}$, but this increase occurs before changing the contact point. At the moment of moving the contact point from one area to the part added, the creep velocity decreases, which in the next part of the monitored section is approaching zero values.

A significant point of view on the described problem is also the intensity of the vehicle's impact on the track, directly affecting the service life of the contact surfaces. Fig. 12 shows the course of the wear number $W_{p}[N]$, i.e., the quantity predicting the intensity of the interaction of the contact pair given by formula:

$$
W_{p}=\left|T_{x} \cdot w_{x}\right|+\left|T_{y} \cdot w_{y}\right|+\left|M_{z} \cdot \varphi_{z}\right|
$$

where $T_{x}[\mathrm{~N}]$ - the longitudinal creep force;

$w_{x}[-]$ - longitudinal creepage;

$T_{y}[\mathrm{~N}]$ - lateral creep force;

$w_{y}[-]$ - lateral creepage;

$M_{z}[\mathrm{Nm}]$ - creep torque;

$\varphi_{z}\left[\mathrm{~m}^{-1}\right]$ - spin creepage.
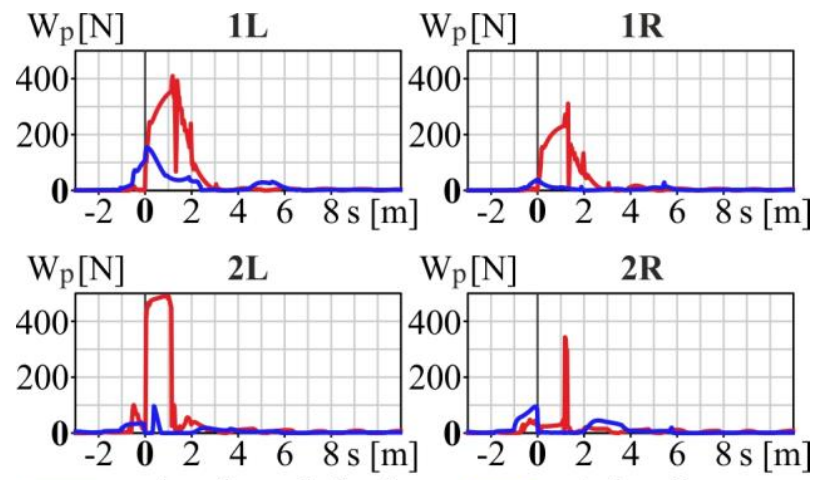

2R

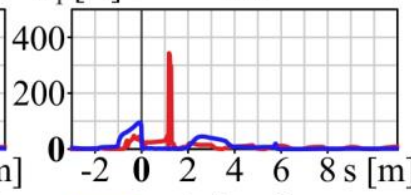

- passing through the frog

- entering the curve

Fig. 12: Course of the sum of the wear number of contact points on the individual wheels of the front bogie

It can be deduced from the courses above that the entrance of the vehicle into the arc using the proposed shaped rail has, as on the vehicle as on the rail, less negative impact than the passage through the frog.

\section{Conclusion}

The paper analyses the effect of the city railways vehicle on the track when passing a specific track sections, where the wheel-rail contact point moves out of the wheel tread. Using the SIMPACK computational program, two similar cases were analysed - passing the frog, where the contact point is moved from the tread to the wheel flange; and the entry into the small radius arc by means of a specially designed rail, that allows the contact point to be moved from the tread to the complemented part. On the basis of the performed analysis, it can be evaluated that changing the contact point when entering the arc by means of the designed, specially shaped rails takes place in a more favourable way, in terms of the steering forces, the angles of attack and the creep velocities. From the wear point of view, it is possible to assume a nearly 4 times longer service life of the proposed shaped rail than the one of a point frog.

\section{Acknowledgement}

The work was supported by the Cultural and Educational Grant Agency of the Ministry of Education of the Slovak Republic in project No. KEGA 077ŽU-4/2017: Modernization of the Vehicles and engines study program. The work was also supported by the project No. APVV-0842-11: Equivalent railway operation load simulator on the roller rig.

\section{References}

[1] Chudzikiewicz, A., Sowinski, B., "Modelling and simulation of trams bogies with fully independently rotating wheels." The Dynamics of Vehicles on Roads and Tracks - Proceedings of the 24th Symposium of the International Association for Vehicle System Dynamics, IAVSD (2015), pp. 1427-1434.

[2] Marqueteeken, A., Van Leuven, A., Kopf, F. "Urban Track. Cost effective track maintenance, renewal \& refurbishment methods. Preventive maintenance of embedded tram tracks Rail wear in curves and special trackwork for trams." (2008) 44p. http://www.urbantrack.eu/images/site/deliverables/ d0208_stib_m24.pdf

[3] Loulová, M., Suchánek, A., Harušinec, J., (2017). "Evaluation of the parameters affecting passenger riding comfort of a rail vehicle", Manufacturing Technology, Vol. 17, Iss. 2, (2017), pp. 224-231.

[4] Tkachenko, V., Sapronova, S., Kulbovskyi, I., Fomin, O. "Research into resistance to the motion of railroad undercarriages related to directing the wheelsets by a rail track." Eastern European Journal of Enterprise Technologies. Vol. 5, Iss. 7-89, (2017), pp. 65-72.

[5] Dižo, J, Blatnický, M. "Use of multibody system dynamics as a tool for rail vehicle behaviour diagnostics“, Diagnostyka, Vol. 17, Iss. 2, (2016), pp. 9-16.

[6] Smetanka, L., Št'astniak, P., "Analysis of contact stresses of theoretical and worn profile by using computer simulation", Manufacturing Technology, Vol. 17, Iss. 4, (2017), pp. 580-585.

[7] Zvolenský, P., Grenčík, J., Pultznerová, A., Kašiar, L., "Research of noise emission sources in railway transport and effective ways of their reduction", Dynamics of Civil Engineering and Transport Structures and Wind Engineering Conference, Vol. 107, (2017). 10 p.

[8] Vossloh Fastening Systems "System W-Tram", (2016), available online https://www.vossloh.com/01_product_finder/ VFS/SystemW-Tram/Vos_Produktbroschuere_Sys-W-Tram_EN.pdf

[9] Vossloh Fastening Systems "Chamber filling elements in covered track”, (2016), available online https://www. vosloh.com/01_product_finder/VFS/Kammerfuellelemente/Vos_Pr oduktbroschuere_Kammerfuellelemente_EN.pdf

[10] Lincoln "Wayside Rail Lubrication" (2011) available online: http://www.lincolnindustrial.com/Catalogs/Uploaded/Catalog_88/R ailroad_W-183-EN-0511.pdf

[11] Sýkora, P., Lelek, T., Sadílek, O.. "Experimental railway vehicle of the Jan Perner Faculty Of Transport." Current problems in rail vehicles 2017 - XXIII.

[12] Hauser, V., Gerlici, J., Lack, T., Loulová, M., Noženko, O., S. Kravčenko, K., O., Prosvirova O., V. "Railway bogie wheelset and curved track segment" Patent application no. a201701589 Kyjiv : Ukrajinskyj instytut promyslovoji vlasnosti (2017). $11 \mathrm{p}$.

[13] Nozhenko, O., Hauser, V., Kravchenko, K., Loulová, M., "Reducing tram car's curve-pasing resistance by double treaded wheel profile", Manufacturing Technology, Vol 18, No. 1., (2018), pp. $79-$ 83.

[14] Ivanov, M. D.; Ponomarev, A. A.; Ieropol'skij B. K. M.. "Tramcars T-3", (1977). 240 p.

[15] Hába, A., Zelenka, J., Kohout, M. "Determination of equivalent loading of turnout frog" Vibroengineering Procedia, Vol.6, (2015), pp. 217-222.

[16] Eken, E., Friberg, R., "Modelling of dynamic track forces generated by tram vehicles", Göteborg: Chalmers University of Technology, Department of Applied Mechanics Division of Dynamics, Sweden, (2015). $130 \mathrm{p}$.

[17] Gerlici, J. Lack, T., "Wheelset/rail geometric characteristics assessment with regard to wheelset rolling", Communications, Vol. 7, Iss. 1, (2005), pp. 5-10.

[18] Zelenka, J., Kohout, M., "Relationship wheel-rail in the conditions of tramcar operations", Jan Perner Faculty Of Transport, (2012), $42 \mathrm{p}$. 
[19] Jenks, W., Jencks, F., Parker, A., Khadka, M., Delaney, E., Chafee, M., "Track Design Handbook for Light Rail Transit", National Academy of Sciencs, (2012), $686 \mathrm{p}$

[20] Evans, J. R., Lee, T. K. Y., Hon, C. C.. "Optimising the wheel/rail interface on a modern urban rail system“, Vehicle System Dynamics, (2009). pp. 119-127.

[21] UIC code 510-2 OR "Trailing stock: wheels and wheelsets. Conditions concerning the use of wheels of various diameters." Paris, (2004).

[22] Hauser, V., Nozhenko, O., Kravchenko, K., Loulová, M., Gerlici, J., Lack, T., "Proposal of a steering mechanism for tram bogie with three axle boxes", Procedia Engineering. Vol. 192 (2017), pp. 289294.

[23] DT-výhybkárna a strojírna "Tram car crossings, components, accessories", (2017), 14 p. available online: https://www.dtvm.cz/dtvs/cz/produkty/tramvajovevyhybky/tramvajove-vyhybky-kolejove-konstrukce-protramvajovou-dopravu/

[24] Nozhenko, O., Kravchenko, K., Hauser. V., Loulová, M.. "Definícia profilu kolesa a kolajnice so špecifickou geometriou", Perner's contacts, No. 2, vol. XII, (2017), pp. 81 - 93.

[25] SIMPACK 9.9.2 (2016) "Documentation" 4556 p.

[26] ŽSR "TNŽ 736361 Geometrical location and layout of $1000 \mathrm{~mm}$ gauge tracks" (2007) Bratislava. 49 p. 